Article

\title{
Biomimetic Sensitive Elements for 2,4,6-Trinitrotoluene Tested on Multi-Layered Sensors
}

\author{
Ana Mihaela GAVRILA ${ }^{1}$, Tanta Verona IORDACHE ${ }^{1, *}$, Carmen LAZAU ${ }^{2}$, Traian ROTARIU ${ }^{3}$, \\ Ileana CERNICA ${ }^{4}$, Hermine STROESCU ${ }^{5}{ }^{\circ}$, Mihai STOICA ${ }^{5}$, Corina ORHA ${ }^{2}$, \\ Cornelia Elena BANDAS ${ }^{2}$ and Andrei SARBU ${ }^{1, *(1)}$
}

1 Advanced Polymer Materials and Polymer Recycling Group, The National Institute for Research\&Development in Chemistry and Petrochemistry ICECHIM, Splaiul Independentei no. 202, Bucharest 060021, Romania; anamihaela.florea@gmail.com

2 Condensed Matter Department, The National Institute for Research\&Development in Electrochemistry and Condensed Matter, Timisoara 300224, Romania; carmen.lazau@gmail.com (C.L.); orha.corina@gmail.com (C.O.); cornelia.bandas@gmail.com (C.E.B.)

3 Chemistry Department, Military Technical Academy “Ferdinand I", Bucharest 050141, Romania; traian.rotariu@mta.ro

4 Ambiental Technology Laboratory, The National Institute for Research\&Development in Microtechnologies IMT, Bucharest 077190, Romania; ileana.cernica@imt.ro

5 Surface Chemistry and Catalysis Laboratory, Institute of Physical Chemistry of the Romanian Academy "Ilie Murgulescu", Bucharest 060021, Romania; hermine25@yahoo.com (H.S.); mihai_stoica2002@yahoo.com (M.S.)

* Correspondence: tanta-verona.iordache@icechim.ro (T.V.I.); andr.sarbu@gmail.com (A.S.); Tel.: +4-0755-159-896 (T.V.I.); +4-0724-237-351 (A.S.)

Received: 18 February 2020; Accepted: 13 March 2020; Published: 15 March 2020

check for updates

\begin{abstract}
In spite of technological progress, most of the current techniques for 2,4,6-trinitrotoluene (TNT) detection are time consuming due to laborious sensor preparation. Thereby, the aim of this work was to enlarge the knowledge for preparing sensitive elements for TNT with the aid of molecular imprinting; a known technique used to deliver biomimetic materials. The study first depicts the auto-assembly mechanism of (TNT) with functional diamino-silanes (i.e., N-(2-aminoethyl)-3-aminopropyl methyl dimethoxysilane), via "double" Meisenheimer complexes. This mechanism is being described herein for the first time and applied further to obtain molecularly imprinted polymer (MIP) films for TNT recognition. For testing the potential application of films as chemical sensor elements, typical rebinding assays of TNT in a liquid state and the rebinding of TNT in a vapor state, using multilayered sensor chips composed of quartz-chromium ( $\mathrm{Cr}$ )-gold ( $\mathrm{Au}$ )-titanium oxide $\left(\mathrm{TiO}_{2}\right)$, were employed. Batch rebinding experiments have shown that thinner films were more efficient on retaining TNT molecules in the first five min, with a specificity of about 1.90. The quartz-Cr-Au- $\mathrm{TiO}_{2}-\mathrm{MIP}$ capacitive sensors, tested in vapor state, registered short response times (less than $25 \mathrm{~s}$ ), low sensitivity to humidity and high specificity for TNT.
\end{abstract}

Keywords: 2,4,6-trinitrotoluene; double Meisenheimer complex; biomimetic sensitive elements; molecular imprinting; multilayered sensors; vapor state detection

\section{Introduction}

2,4,6-Trinitrotoluene (TNT) is produced in enormous quantities for military munitions, being the most widely used energetic material. Yet, its production leads to both environmental and public security issues and for this reason, the development of sensing methods for nitro-aromatic explosives has increased in recent years. Some of the current methods refer to fluorescence [1-5], spectroscopy [6,7], 
immunochemistry [8], ion mobility spectrometry [9,10], Raman spectroscopy [11-13] or surface plasmon resonance (SPR) [14-16].

The fact that TNT is an electron-deficient aromatic, given by the three nitro substituents, can be of help when developing new sensitive materials. For example, the sensing mechanism can rely on creating stabile Meisenheimer complexes of TNT with amino-based substrates $[1,2,6,7,11,14-16]$. A Meisenheimer complex is an anionic complex formed by the attack of a nucleophile upon one of the aromatic-ring carbons during the nucleophilic aromatic substitution reaction. In this respect, two types of Meisenheimer complexes can be formed, meaning $\sigma^{\mathrm{H}}$-complex or $\sigma^{\mathrm{X}}$-complex, corresponding to the non-substituted or substituted aromatic ring. The formation of such complexes is allowed so far for developing paper-based sensors [7] and SPR sensors [16]. In this direction, the literature only attests the use of mono-functional amines for TNT complexation, to form "single" Meisenheimer complexes (1: 1= Amine: TNT).

More sensitive materials can be prepared if molecular imprinting (MI) techniques are approached [17-19]. It is known that MI is a facile method to tailor biomimetic materials by creating complementary recognition sites in an organic/inorganic matrix for targeted analytes [20,21]. This technology consists of polymerizing assemblies, generated by reversible interactions between functional monomers and template molecules, with the formation of molecularly imprinted polymers (MIPs). The template removal creates complementary cavities in shape, size and electronic entourage in the polymer matrix, which are responsible for the specific recognition of the target analyte [22]. Materials generated by this technique present high chemical resistance, thermal stability, good mechanical properties and reusability [23]. Hence, considering the advantages of MI, many scientists have been using this technique to develop various advanced materials [24-26], such as membranes [27,28], beads [29], particles [30,31], micro- and nano-gels [32,33] or thin films [34,35], to be utilized as separation tools [36], catalysts [37] or sensors and biosensors [38] for metal recovery [39,40], drug delivery [41] and ternary mixture separation [42]. In this context, some authors have already reported the use of MI for developing TNT-MIPs using surface imprinting of silica nanoparticles [43] and nanotubes [44] or bulk imprinting of films [16,27]. For instance, the MIP films prepared by Florea et al. [27] were prepared using the wet phase-inversion method, but presented low adhesion to the substrate and detached after several washing procedures, and the TNT-MIP coatings prepared by Gao et al. [43] and Xie et al. [44] were prepared using two-step procedures starting from the surface pre-modification of silica and alumina, respectively, with functional silane, followed by MIP grafting. In these MI approaches, as well, the recognition mechanism of TNT relied on weak hydrogen bonds or $\pi-\pi$ interactions between mono-functional monomers and TNT.

In light of aforementioned studies, the present study brings to the audience a very practical procedure to prepare thin TNT-MIP films, by direct spray deposition of a sol-gel precursor solution on glass substrates. Another advantage of this newly presented method for films preparation refers to the low energy consumption in terms of low temperatures for polycondensation (i.e., room temperature) and for the curing/ aging of films $\left(55^{\circ} \mathrm{C}\right)$. Moreover, the present work proposes a new monomer-template auto-assembly mechanism, in order to enhance the specificity of films prepared by sol-gel derived techniques. This mechanism implies the formation of "double" Meisenheimer polymerizable $\sigma^{\mathrm{X}}$-complexes between TNT and bi-functional monomers, i.e., diamino-silanes, and it is being reported herein for the first time. The TNT-MIP films obtained by polymerizing this "double" Meisenheimer complex are further tested for specificity and response time in liquid and vapor state, to demonstrate their potential application as biomimetic sensitive elements in sensors development. The rationale for choosing chemical sensors [45] as a potential application is related to the fact that chemical sensors are generally sensitive enough to detect small amounts of chemical vapors, due to their ability to change their electrical characteristics, such as resistance or capacitance [46,47]. To prepare the multilayered sensor, a particular type of transducer composed of quartz-chromium (Cr)-gold $(\mathrm{Au})$-titanium oxide $\left(\mathrm{TiO}_{2}\right)$ was employed, as it is proven to be the most efficient way to detect TNT without additional signal amplifiers [26]. 


\section{Materials and Methods}

\subsection{Raw Materials}

For the preparation of precursor solutions for films deposition, $N$ - (2-aminoethyl) -3-aminopropylmethyldimethoxysilane (commercial name 1141-D, 98\%, Sigma-Aldrich, St. Louis, MI, USA) and 2,4,6-trinitrotoluene (recrystallized from methanol, 99\%, TNT, Military Technical Academy, Bucharest, Romania) were used as functional monomer and template, respectively. Other materials like ethanol (analytical grade, Chimopar, Bucharest, Romania), ammonium hydroxide (25\% solution, analytical grade, Chimopar), 1N hydrochloric acid (analytical grade, Chimopar) and distilled water were used as solvents or catalysts. The interference compound in the selectivity trials was 1,3-dinitrobenzene (DNB, 99\%, Military Technical Academy). The quartz supports were purchased from Sigma-Aldrich. The chromium and gold foils (99.99\% trace metals, Sigma-Aldrich) used for sputtering and the precursors for preparing the $\mathrm{TiO}_{2}$ layer (i.e., titanium tetrachloride (TiCl4, 99\%, Merck, Kenilworth, NJ, USA) and oxalic acid solution $\left(\mathrm{C}_{2} \mathrm{H}_{2} \mathrm{O}_{4}, 5 \mathrm{wt} . \%\right.$, Merck)) were used as received. The synthesis and tests, which implied the use of TNT, were carried out at the Military Technical Academy, Explosives and Ammunition Lab in Bucharest, Romania.

\subsection{Synthesis of Molecularly Imprinted Polymer (MIP) Films for TNT Recognition}

The synthesis of MIP films referred to generating double Meisenheimer polymerizable complexes by monomer-template auto-assembly of N-(2-aminoethyl)-3-aminopropyl methyl dimethoxysilane (1141-D) and TNT. The auto-assembly mechanism of TNT with 1141-D was based on charge transfer complexing interactions with the formation of particular $\sigma^{\mathrm{X}}$-Meisenheimer complexes, corresponding to the substituted aromatic ring of TNT (as depict in Figure 1). The formation mechanism of $\sigma^{\mathrm{X}}$-Meisenheimer complex, where $\mathrm{x}$ is the methyl group of the substituted aromatic nucleus (position 1) of TNT, was proposed by several authors for monofunctional-amines and nitroaromatics $[1,2,6,7,48]$ and adapted in this study for the formation of "double" $\sigma^{\mathrm{X}}$-Meisenheimer complexes. Further on, the double Meisenheimer complexes were polymerized using a sol-gel derived technique adapted from Stoica et al. [49] to create MIP films.

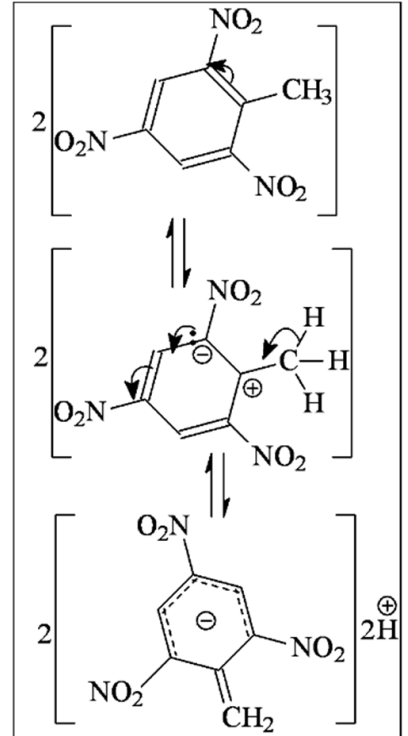

(1) TNT in ethanol

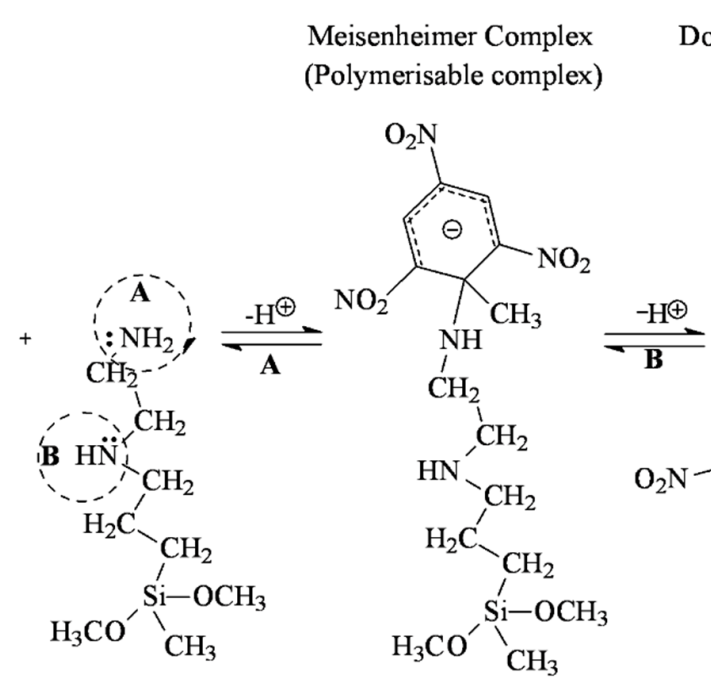

(2) 1141-D
(3) TNT:1141-D=1:1
Double Meisenheimer Complex (Polymerisable complex)<smiles>CO[Si](C)(CCN(CCNC1(C)C([N+](=O)[O-])=CC([N+](=O)[O-])=CC1[N+](=O)[O-])C(C)(C)C(C)C(=O)[O-])OC</smiles>

(4) TNT:1141-D=2:1

Figure 1. The auto-assembly mechanism based on a charge transfer complexing interaction between TNT (1) and diamino-functional organosilane monomer 1141-D (2) in ethanol at $24{ }^{\circ} \mathrm{C}$, with the formation of single (3) and double (4) Meisenheimer $\sigma^{\mathrm{X}}$-complexes. 


\subsubsection{Study of Monomer-Template Auto-Assembly Via Double Meisenheimer Complexes}

The first step in designing stabile polymerizable complexes was the study of monomer-template auto-assembly, which consisted of 1141-D titration with TNT. In this respect, ethanol was used as solvent for preparing the two solutions. The spectral-photometric titration involved the following procedure: a solution of 1141-D $(0.88 \mu \mathrm{M})$ was titrated gradually with a TNT stock solution $(88 \mu \mathrm{M})$ directly in the quartz cuvette of the spectrophotometer. In the first step, a portion of $4 \mu \mathrm{L}$ from the TNT stock solution was added over $2 \mathrm{~mL}$ of 1141-D solution (to obtain a starting TNT concentration of $0.18 \mu \mathrm{M})$ and the sample was shaken and left to rest for the complexation to take place. After five $\mathrm{min}$, the absorbance was measured and another portion of $4 \mu \mathrm{L}$ from the TNT solution was applied. The procedure was continued until equilibrium was established (absorbance plateau).

\subsubsection{Films Preparation by Sol-Gel Derived Techniques}

In order to obtain TNT-MIP films, two solutions were prepared separately, as follows: the precursor solution containing the functional monomer (1141-D) and the template (TNT) in $1 \mathrm{~mL}$ of ethanol, and the catalyst solution containing $0.565 \mathrm{~mL}$ ammonia hydroxide and $0.225 \mathrm{~mL}$ of water. The two solutions were mixed and maintained at room temperature $\left(24^{\circ} \mathrm{C}\right)$ under continuous stirring (at $200 \mathrm{rpm}$ ) for $2 \mathrm{~h}$ (sol-gel time, $t_{\mathrm{sg}}$ ), while hydrolysis of the -OR groups of 1141-D occurred, with the formation of sols. The resulting solution was applied by spraying directly onto degreased glass slides to form crosslinked networks by alcohol/aldol polycondensation. The degreasing of glass slides was necessary to remove greasy substances, which may reduce the surface contact of films with the support and implicitly cause loss of adherence. Degreasing was performed by extensive washing of the glass slides with alkaline solution $(3 \times 10 \mathrm{~mL}$ of $1 \mathrm{~N} \mathrm{NaOH}$ solution per glass slide). The final films were obtained after a two-step maturation procedure considering a temperature treatment at $24{ }^{\circ} \mathrm{C}$ for $48 \mathrm{~h}$, followed by a temperature treatment at $55^{\circ} \mathrm{C}$ for $48 \mathrm{~h}$. Afterward, the films were washed with ethanol $(1 \times 20 \mathrm{~mL})$ for $4 \mathrm{~h}$ at $24^{\circ} \mathrm{C}$, assisted by ultrasonication for removing reaction residues. Using the same synthesis methodology, but without the addition of TNT, non-imprinted films (NIPs) were also prepared, to be used as a reference in highlighting the imprinting effect.

It is important to note that the specificity and binding capacity of MIP films depend upon the efficiency of the template removal process, as leaching may affect the measured values for the two parameters. Yet, it was found that TNT remains blocked in the films with over $4-5 \mu \mathrm{m}$ thickness, even after 5 washing cycles and the films thinner than $100 \mathrm{~nm}$ can detach easily from the glass slides after washing. Therefore, the performance of films was studied at the thickness limits, where both the removal of template and adhesion to the glass slides were practically achievable. In this respect, the sol-gel deposition method allowed us to manipulate the thickness of films by dilution of the precursor solution and, hence, two film thicknesses were targeted as follows: $2 \mu \mathrm{m}$ (identified with the notation C) and $200 \mathrm{~nm}$ (identified with the notation D). The recipes for the precursor solutions used to obtain TNT-MIP and NIP films with various thicknesses are given in Table 1. The appearance of both (D) and (C) films (noted TNT-MIP (D) and TNT-MIP (C), respectively) was orange-brown, due to the formation of $\pi-\pi$ complexes $[1,2,6,7,48]$ between TNT and 1141-D, while the control samples [noted NIP (D) and NIP (C), respectively] were transparent (also see Figure S1).

Table 1. Recipes for 2,4,6-trinitrotoluene-molecularly imprinted polymer (TNT-MIP) and non-imprinted polymer (NIP) film pairs.

\begin{tabular}{cccc}
\hline Polymer Film & 1141-D (mmoles) & TNT (mmoles) & 1141-D:TNT (M/M) \\
\hline TNT-MIP (C) & 0.726 & 0.073 & $10: 1$ \\
NIP (C) & 0.726 & 0 & 0 \\
TNT-MIP (D) & 0.363 & 0.036 & $10: 1$ \\
NIP (D) & 0.363 & 0 & 0 \\
\hline
\end{tabular}


Further on, the TNT was extracted from the TNT-MIP films with a hydrochloric acid solution $1 \mathrm{~N}(1 \times 40 \mathrm{~mL})$, for $48 \mathrm{~h}$ at $24^{\circ} \mathrm{C}$. The extraction of TNT with a hydrochloric acid solution was by far the best method to disrupt the $\pi-\pi$ interactions in the double Meisenheimer complex, after several unsuccessful trials of using ethanol, acetonitrile or acetic acid solvent mixtures. The extracted films were ultimately dried to a constant weight at $80^{\circ} \mathrm{C}$ (approximately $48 \mathrm{~h}$ ). The films were prepared in several batches. For each batch of films, 20 glass slides were used. The compatibility of films with the glass substrates was quite high. The thin films detached from the glass after 2 days and the thick films after 4 days of being submerged in the $1 \mathrm{~N}$ hydrochloric acid solution.

\subsection{Preparation of Quartz-Cr-Au-TiO ${ }_{2}-M I P$ Sensors}

The quartz-Cr-Au- $\mathrm{TiO}_{2}$ supports were prepared by combining the know-how from two different patents $[26,28]$. First of all, the quartz support was cleaned with isopropyl alcohol (IPA) and deionizer water and dried in nitrogen flow. Afterwards, a thin chromium $(\mathrm{Cr})$ film was deposited on the quartz support to obtain a better adherence for the following gold $(\mathrm{Au})$ layer; otherwise, the hydrothermal conditions would affect or destroy the integrity of the Au layer. In this respect, the $\mathrm{Cr}$ film was deposited through the sputtering technique, using an Emitech K975X device (Emitech, Dubai, UAE) with $1.91 \times 10^{-3}$ vacuum and $0.1 \mathrm{~nm} \cdot \mathrm{s}^{-1}$ deposition rates, and sintered at $600{ }^{\circ} \mathrm{C}$ for $60 \mathrm{~min}$ in nitrogen atmosphere. The following Au layer, with approximately 10-20 nm thickness, was deposited on the $\mathrm{Cr}$ layer using the same sputtering technique $\left(1.91 \times 10^{-3}\right.$ vacuum and $0.14 \mathrm{~nm} \cdot \mathrm{s}^{-1}$ deposition rates $)$ and sintered at $600{ }^{\circ} \mathrm{C}$ for $60 \mathrm{~min}$ in nitrogen atmosphere.

The $\mathrm{TiO}_{2}$ films were obtained and deposited over the quartz-Cr-Au substrate in situ, using a similar hydrothermal method described by Lazau et al. $[27,28]$, that uses titania tetrachloride $\left(\mathrm{TiCl}_{4}\right)$ and oxalic acid $\left(\mathrm{C}_{2} \mathrm{H}_{2} \mathrm{O}_{4}\right)$ as precursors. The protocol considered using $3 \mathrm{~mL}$ of $\mathrm{TiCl}_{4}$, as Ti precursor, added dropwise into $41 \mathrm{~mL}$ of $\mathrm{C}_{2} \mathrm{H}_{2} \mathrm{O}_{4}$ solution (5 wt.\%), followed by stirring (200 rpm) in ambient condition for $60 \mathrm{~min}$. The obtained stable gel was introduced into a Teflon autoclave (fullness degree about $80 \%$ ), together with the quartz-Cr-Au substrate, previously washed with ethanol, deionised water and acetone, which was suspended with a clamping system (Figure S2). In order to optimize the stability of $\mathrm{TiO}_{2}$ films, the hydrothermal synthesis was performed either at $150{ }^{\circ} \mathrm{C}$ or $200{ }^{\circ} \mathrm{C}$, in an electric oven. After $10 \mathrm{~h}$, the autoclave was cooled naturally to room temperature and the samples were rinsed extensively with deionised water and dried in an oven at $60^{\circ} \mathrm{C}$ for $2 \mathrm{~h}$. Further on, the stability of the $\mathrm{TiO}_{2}$ film deposited on the quartz-Cr-Au substrate was verified through adherence tests in the ultrasonic bath (revealing that both types of films were adherent for $60 \mathrm{~min}$ after immersion in deionized water at $24^{\circ} \mathrm{C}$ ).

In the next step, only TNT-MIP (D) films were deposited on the quartz-Cr-Au- $\mathrm{TiO}_{2}$ supports. In this respect, the preparation method of TNT-MIP (D) films was provided in Section 2.2. Finally, the electrical connections for the quartz-Cr-Au- $\mathrm{TiO}_{2}-\mathrm{MIP}$ sensor with the electronic mask (EM) were made using silver paste and the whole assembly was protected with an epoxy resin layer (Figure S3). The overall assembly was built to work as a multi-plate capacitor [47].

\subsection{Employed Characterisation Methods}

The films deposited on glass slides were analyzed using a spectral-elliposometric method. The measurements were performed with a UV-VIS-NIR Ellipsometer VASE ${ }^{\circledR}$ (J.A. Woollam Co, Inc., Lincoln, NE, USA) in the 190-1000 nm wavelength range at $70^{\circ}$ AOI with a $10 \mathrm{~nm}$ step and 20 scans/measurement (microspot). To avoid the effect of 'backside reflection', a translucent scotch tape was mounted on the back of the glass substrate. The monomer-template assembly experiments (Section 2.2.1) and TNT batch re-binding experiments (Section 2.5) were performed using the UV-2501-PC spectrometer (Shimadzu Co., Tokyo, Japan) in the 200-1000 nm wavelength range, with a $10 \mathrm{~mm}$ quartz cuvette.

For evaluating the topography of films, atomic force microscopy measurements were made using the XE-100 microscope from Park Systems (Tokyo, Japan), in true non-contact TM mode, as recommended for soft samples. The scanner of the XE100 apparatus was equipped with flexure-guided, 
cross talk eliminated scanners, thus allowing the imaging of very small objects at the nanometre scale. All AFM images were recorded with sharp tips ( $<8 \mathrm{~nm}$ tip apex), NCHR type from Nanosensors TM, of approximately $125 \mathrm{~mm}$ length, $30 \mathrm{~mm}$ width, spring constant $42 \mathrm{~N} \cdot \mathrm{m}^{-1}$, and $330 \mathrm{kHz}$ resonance frequency. The AFM images were processed with the XEI program (v 1.8.0-Park Systems) for displaying purposes and roughness evaluation.

The crystallinity of $\mathrm{TiO}_{2}$ thin films synthesized at different temperatures $\left(150{ }^{\circ} \mathrm{C} / 200^{\circ} \mathrm{C}\right)$ was measured by X-ray diffraction (XRD) using PANalytical X'PertPRO MPD Diffractometer (PANalytical, Eindhoven, The Netherlands) with a copper tube. The surface morphologies of $\mathrm{TiO}_{2}$ films and of the MIP films (deposited on glass slides and on the quartz-Cr-Au support) were investigated by scanning electron microscopy (SEM) with an Inspect S PANalytical apparatus (PANalytical, Almelo, The Netherlands) equipped with an energy dispersive X-ray analysis (EDX) detector, allowing the simultaneous elemental analysis of the $\mathrm{TiO}_{2}$ films.

\subsection{Protocols in Batch Rebinding Experiments of TNT}

The rebinding tests consisted of contacting the films with $35 \mathrm{~mL}$ of feed solution containing TNT (experiments conducted in batch, at room temperature $24^{\circ} \mathrm{C}$ ) and measuring the initial and the final concentration of TNT. The concentration of TNT from the supernatants was quantified using a calibration equation $A=f(C)\left(A=17.717+0.0513 C_{T N T}, r^{2}=0.9978\right)$, where $A$ represents the absorbance (arbitrary units) at $273 \mathrm{~nm}$ of the sample $C_{\mathrm{TNT}}\left(\mathrm{g} \cdot \mathrm{L}^{-1}\right)$. Calibration of TNT was performed in ethanol in the $0.2-0.002 \mathrm{~g} \cdot \mathrm{L}^{-1}$ concentration range.

Using various concentrations of TNT in ethanol (i.e., $0.20,0.02$ and $0.002 \mathrm{~g} \cdot \mathrm{L}^{-1}$ ), the adsorbed amount of TNT was measured after a period of $8 \mathrm{~h}$. Herein, the concentration limits chosen for the study, meaning 0.002 and $0.2 \mathrm{~g} \cdot \mathrm{L}^{-1}$, represented the lowest quantity of TNT that can be visually detected by complexation and the highest quantity of TNT that can be detected by UV without further dilution, respectively. TNT rebinding measurements with various TNT concentrations were repeated 2 times, using different MIP/NIP films. Afterward, the rebinding of TNT was studied in the first $120 \mathrm{~min}$ after contact with a TNT solution in ethanol of $0.02 \mathrm{~g} \cdot \mathrm{L}^{-1}$. This complementary study revealed the rebinding capacity and the specificity of adsorption at various moments of time for the more performant (D) films.

Rebinding capacities, $Q$ (mg TNT $\cdot \mathrm{g}^{-1}$ polymer film), of TNT-MIP and NIP films were calculated using the following equation: $Q=\left(C_{N, i}-C_{N, f}\right) V_{S} / m_{P}$, \{where $C_{N, i}\left(\mathrm{~g} \cdot \mathrm{L}^{-1}\right)$ and $C_{N, f}\left(\mathrm{~g} \cdot \mathrm{L}^{-1}\right)$ are the initial and final concentration of TNT in the feed solution; $m_{p}(\mathrm{mg})$ the films weight (meaning $50 \pm 1.1 \mathrm{mg}$ for the thick films (C) and $10 \pm 0.4 \mathrm{mg}$ for the thin films (D)); and, $V_{S}(\mathrm{~L})$ is the volume of the feed solution (i.e., $35 \mathrm{~mL}$ ). Imprinting factors, $F$, expressed by the relation $Q_{M I P} / Q_{N I P}$ (where $Q_{M I P}$ and $Q_{N I P}$ are the rebinding capacities of TNT-MIP and NIP, respectively) were calculated in the attempt to quantify the specificity of MIP films for TNT, compared to their corresponding control films, NIPs.

\subsection{Testing Platform for EM-Quartz-Cr-Au-TiO $\mathrm{O}_{2}-\mathrm{MIP}$ Sensors}

The testing platform for detecting dangerous agents was developed by specialists from the Military Technical Academy, Explosives and Ammunition Lab. The Explosives Detection Test Platform (EDTP) contained three air modules/ trails as follows: a first module that allowed a flow of air with certain humidity and temperature saturated with TNT, a second module generating adjustable flow rates of pure air with a certain humidity and temperature and a third module that allowed the introduction of known interfering concentrations. The performance of EM-quartz-Cr-Au- $\mathrm{TiO}_{2}-\mathrm{MIP}$ sensors was registered using an Agilent Technologies E4982A RLC Bridge, with a response time of $0.9 \mathrm{~ms}$ and a minimum accuracy of $\pm 0.85 \%$. All the measurements were performed at an ambient temperature of $26{ }^{\circ} \mathrm{C}$. Humidity ranged from a maximum of $5 \%$ (pure dry air) to $31 \%$ and the test frequency was kept constant at $1 \mathrm{MHz}$. In order to determine the specificity of sensor elements, TNT detection tests were also performed in the presence of dinitrobenzene (DNB). 


\section{Results and Discussion}

\subsection{Double Meisenheimer Complex Formation}

According to Figure 1, it was assumed that the final Meisenheimer complex obtained in ethanol was formed from 2 moles of TNT and 1 mole of 1141-D due to the two amino complexation centres of the monomer. This complexation mechanism was confirmed by the spectral-photometric titration of 1141-D with TNT in the UV-visible range (Figure 2a). After the first portion of TNT, an absorbance increase was observed at $508 \mathrm{~nm}$ (assuming to be the specific wavelength of this double complex, as the reported wavelength for single Meisenheimer complexes is around $530 \mathrm{~nm}$, [7]) and kept rising until equilibrium was reached (as presented in Figure $2 b$ ). The molar relationship between the template and the functional monomer was determined using the "mole ratio method", where the X XNT/1141D is the molar ratio between TNT and 1141-D. The point of intersection of the two linear variations in the graph represented the molar ratio of TNT and 1141-D in the complex. The resulted molar ratio of 1.74 suggested the formation of a double complex in the form of 1.53: $0.88=$ TNT: $1141-\mathrm{D}(\mathrm{M} / \mathrm{M})$, similar to the one proposed in Figure 1. Unlike the colorimetric complexation of TNT based on the single Meisenheimer complex formation [7], the method for TNT complexation using 1141-D was more sensible, as the formed double Meisenheimer complex was visible (pale pink colour) with the naked eye at very low TNT concentration $(\sim 0.18 \mu \mathrm{M})$.
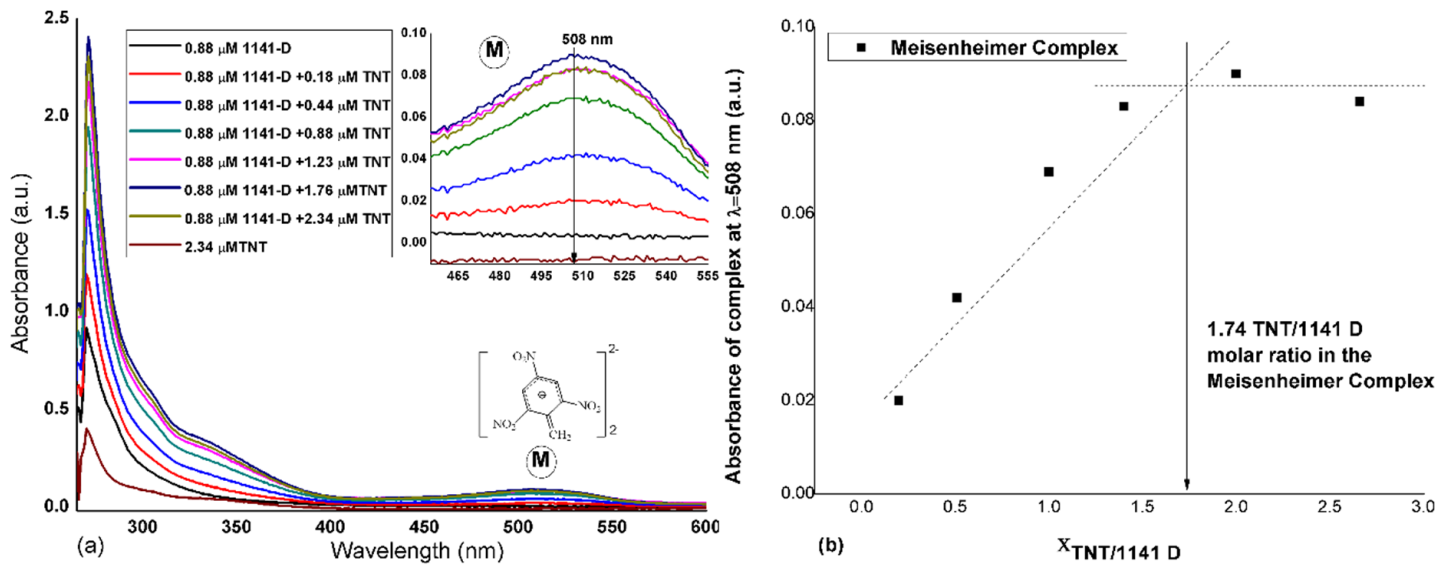

Figure 2. Monomer-Template Assembly in ethanol at $24{ }^{\circ} \mathrm{C}$ : (a) Spectral-photometric titration of 1141-D with TNT with the formation of double Meisenheimer complexes at $508 \mathrm{~nm}$ (inset); (b) Double Meisenheimer complex formation at $508 \mathrm{~nm}$ wavelength in the form of 1.53:0.88 = TNT:1141-D (M/M), as function of the molar ratio between TNT and 1141-D $\left(\mathrm{X}_{\mathrm{TNT} / 1141 \mathrm{D}}\right)$.

\subsection{Spectroscopy Results for the Films Deposited on Glass Slides}

The measurement of refractive index, $n$, for MIPs (before TNT extraction) and NIPs represented a very good method for highlighting the imprinting effect [50]. Transmittance profiles were also proof of the auto-assembly mechanism of 1141-D monomer and TNT, which suggested that double Meisenheimer assemblies were formed and cured by polycondensation/cross-linking in the organosilica network. The refractive index variation and the transmittance profiles of TNT-MIP (D) and (C) films before TNT extraction, evaluated in the 200-1000 nm wavelength range against their corresponding NIPs, are given in Figure $3 a, b$ respectively. For fitting the experimental ellipsometry data, the Cauchy Model for the transparent area was used [51]. This method allowed for simultaneous evaluation of the films' thicknesses. The thickness difference (as given in Table 2) for both the thin (D) and the thick (C) film pairs was high, due to the different growth mechanism of the organosilica matrix upon TNT addition. Yet, the roughness of the samples and the values of the mean square error (MSE) were small, which indicated a good fitting of experimental data. 

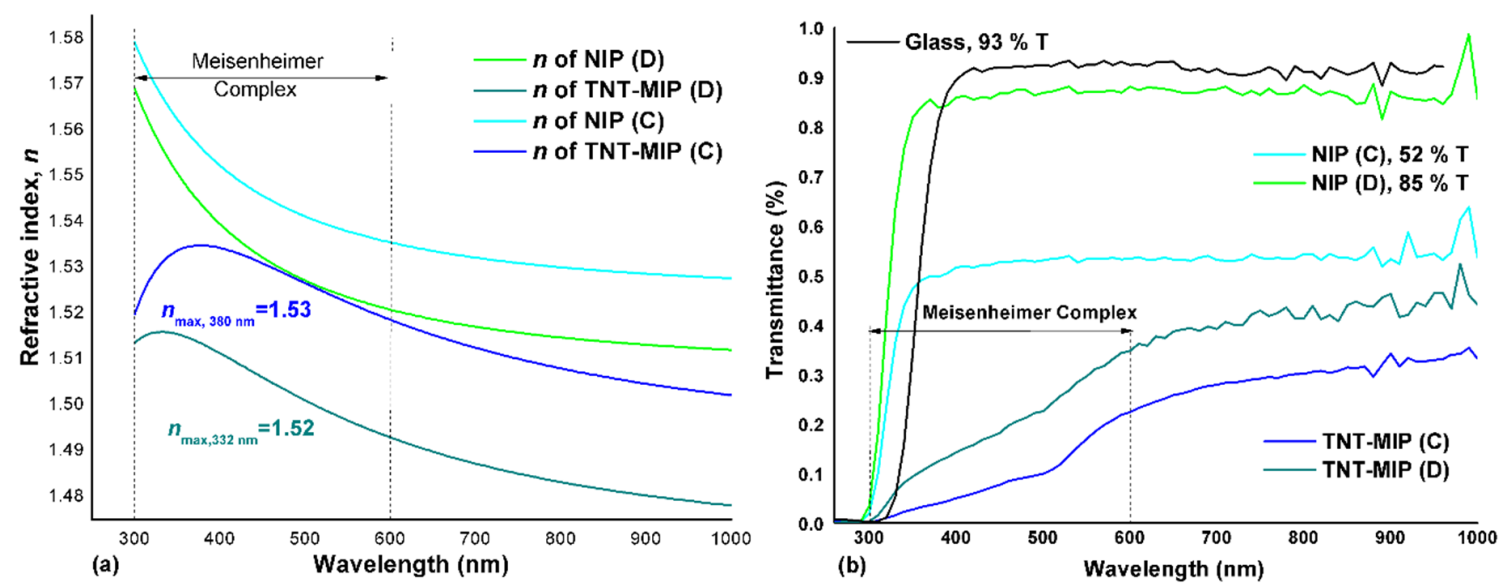

Figure 3. Optical parameters of TNT-MIP films before TNT extraction compared to their corresponding NIPs: (a) Refractive index, $n$, variation in the 200-1000 nm wavelength range; (b) Transmittance profiles, in the $200-1000 \mathrm{~nm}$ range.

Table 2. Films thickness ( $\left.\mathrm{d}_{\text {layer }}\right)$, roughness and mean square error (MSE) determined by ellipsometry.

\begin{tabular}{cccc}
\hline Film & $\mathbf{d}_{\text {layer }}(\mathbf{n m})$ & Roughness $(\mathbf{n m})$ & MSE \\
\hline NIP (C) & 77.32 & 0.00 & 0.52 \\
NIP (D) & 24.24 & 2.45 & 0.31 \\
TNT-MIP (C) & 2174.19 & 0.03 & 0.98 \\
TNT-MIP (D) & 231.57 & 0.77 & 1.24 \\
\hline
\end{tabular}

When evaluating the transmittance profiles, pronounced modifications for both (D) and (C) TNT-MIP films were registered, particularly in the 300-550 nm wavelength regions. The observed differences were due to the presence of the double Meisenheimer complex in the films structure (determined around $508 \mathrm{~nm}$, according to complexation experiments). At the same time, the refractive index presented important changes due to the extended $\pi-\pi$ conjugation introduced by TNT [48], but also due to the film thickness (as compared to the control NIP films). It can also be noted that the maximum values of $\mathrm{n}$, for the (C) and (D) TNT-MIP films, also shifted towards higher wavelengths (towards the red zone) compared to the control samples, as the resonant wavelength changed with the presence and the concentration of the double Meisenheimer complex. Nevertheless, both (D) and (C) TNT-MIP films presented similar trends of transmittance and refractive index, indicating that the auto-assembly mechanism that generated double Meisenheimer complexes was reproducible, even at lower concentrations of the precursor solutions and, implicitly, for lower film thicknesses.

\subsection{Batch Rebinding Studies for Films Deposited on Glass Slides}

The most common and simplest way to highlight the effect of imprinting for the TNT-MIP films referred to batch rebind studies of TNT from liquid samples. Hence, the specificity for TNT was evaluated by determining the rebinding capacities, $\mathrm{Q}\left(\mathrm{mg} \cdot \mathrm{g}^{-1}\right)$ and imprinting factors, $F$ of films (Figure 4). In this respect, the quantification of bonded TNT was performed indirectly, by measuring the un-bonded TNT from the supernatants at $273 \mathrm{~nm}$ (specific wavelength for TNT absorbance). 

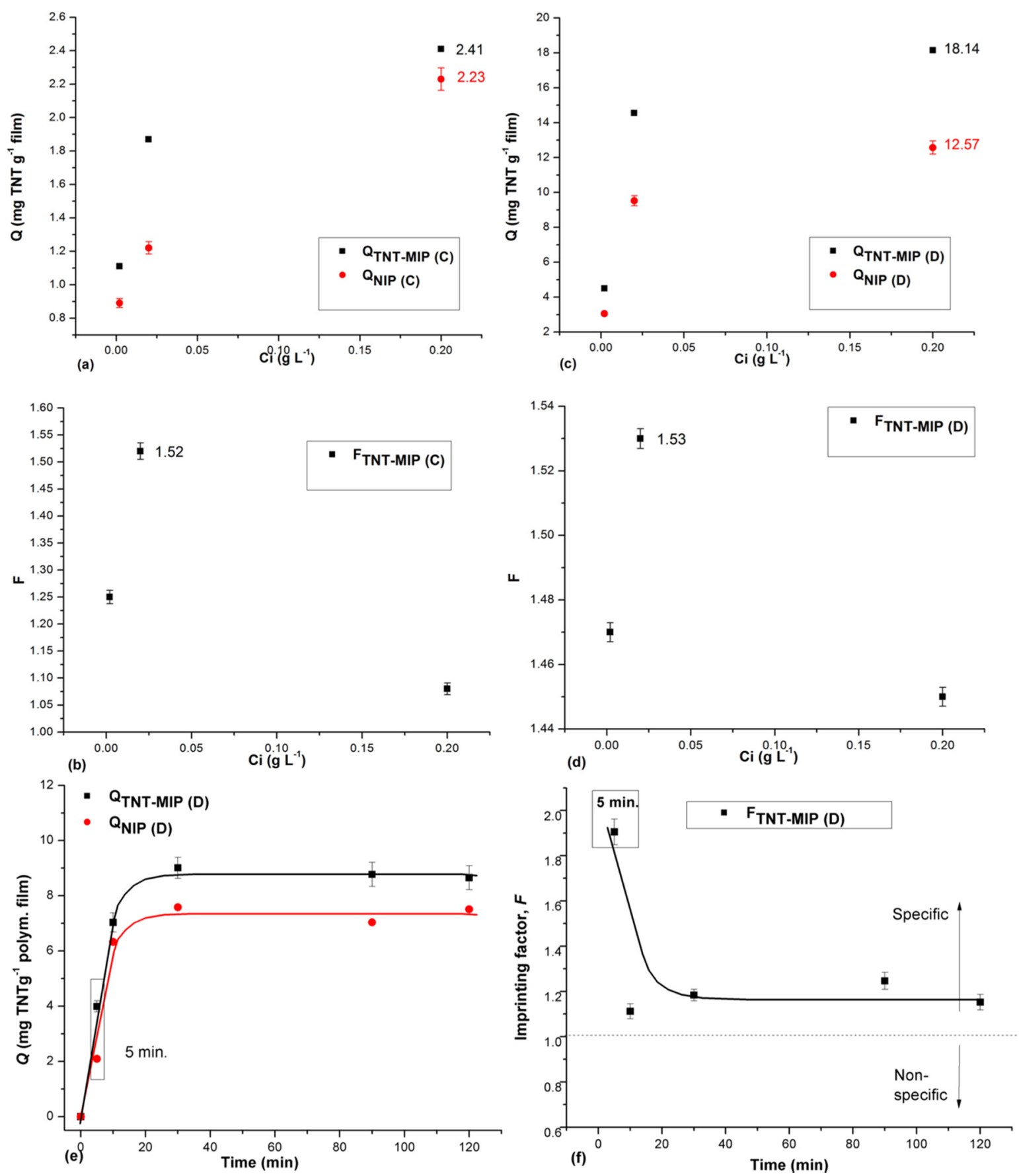

Figure 4. Rebinding of TNT in batch adsorption measurement: $(\mathbf{a}, \mathbf{c})$ Variation of re-binding capacities, $Q$, after $8 \mathrm{~h}$ of contact with various TNT feed solutions, $C_{i}\left(0.002-0.20 \mathrm{~g} \cdot \mathrm{L}^{-1}\right) ;(\mathbf{b}, \mathbf{d})$ Variation of imprinting factors, F after $8 \mathrm{~h}$ of contact with various TNT feed solutions, $C_{i}\left(0.002-0.20 \mathrm{~g} \cdot \mathrm{L}^{-1}\right)$; (e) Variation of re-binding capacities, $Q$, for TNT-MIP/NIP (D) films, over time (5-120 min) after contact with a TNT feed solution, $C_{i}$, of $0.02 \mathrm{~g} \cdot \mathrm{L}^{-1}$ and (f) Variation of imprinting factors, $F$, for TNT-MIP/NIP (D) films over time (5-120 min) from a TNT feed solution, $C_{i}$, of $0.02 \mathrm{~g} \cdot \mathrm{L}^{-1}$.

When the concentration of TNT feed solution (Ci) was varied between $0.002-0.20 \mathrm{~g} \mathrm{TNT} \cdot \mathrm{L}^{-1}$, the binding capacities (Figure $4 a, c$ ) indicated that thinner films were more efficient for rebinding TNT. As a result, the $Q$ values for the NIP/TNT-MIP (D) films were above the ones registered for the thick films (C). In agreement with the binding capacity, the imprinting factors, $F$, were also slightly higher for the TNT-MIP (D) films over this concentration range (the highest $F$ value 1.53, being registered at $0.02 \mathrm{~g}$ $\mathrm{TNT} \cdot \mathrm{L}^{-1}$, Figure $4 \mathrm{~d}$ ). Nevertheless, all the $F$ values were above 1.0, suggesting that rebinding was 
specific for the studied TNT concentration domain. Hence, it can be stated that the imprinting effect was clearly highlighted through these preliminary batch rebinding experiments and that TNT-MIP (D) films were more efficient for TNT recognition and retention. Thereby, only the NIP/TNT-MIP (D) film pairs were further investigated. In this respect, Figure 4e shows the variation of binding capacity over time, after contact with the NIP/TNT-MIP (D) films, and indicates that the binding equilibrium was attained after $90 \mathrm{~min}$. Here, as well, the binding capacity profile over time for the TNT-MIP (D) film compared to the control NIP film suggested a clear effect of imprinting. Convenient for the application, the most specific rebinding (according to the calculated imprinting factor, $F$, in Figure $4 \mathrm{f}$ ) was recorded in the first five $\mathrm{min}$, after which, the specificity decreased with the time of contact from 1.90 (at $5 \mathrm{~min}$ ) to 1.2 (at $120 \mathrm{~min}$ ).

It is also worth mentioning that after 120 min of contact with the TNT solution, both TNT-MIP (D) and NIP (D) films were orange-colored, due to Meisenheimer complexes forming at the interface (according to Figure S4). This shift of color from pink to orange was probably due to the fact that rebinding of TNT was made in the solid phase. Plus, a visual difference was noticed between the imprinted and the non-imprinted films; the TNT-MIP films seem to present some intense colored dots on the surface, which may be associated with the specific binding sites.

\subsection{Microscopy of Films Deposited on Glass Slides}

The batch adsorption measurements indicated that TNT was bonded more specifically and in higher extents by the TNT-MIP (D) films and one explanation to this behavior can be related to the morphology of films. The microscopy of films highlighted the effect of imprinting, which, in this fortunate case, improved the films forming properties and also prevented the appearance of intrinsic cracks. The 3D and 2D scans (Figure 5) of TNT-MIP (D) and TNT-MIP (C) films, recorded by atomic force microscopy, revealed more discrete surface arrangements for (D) films. Hence, this particular morphology of (D) films translates into a higher contact area with the TNT feed solution (providing access toward the imprinted sites [52]); and thus, more TNT molecules can be absorbed specifically. The topography scans of MIP and NIP films are also consistent with the thickness, as evaluated by ellipsometry. The steric hindrance brought by the formation of the Meisenheimer complexes led to a different growth mechanism of the silica network, for MIP films, which would explain the difference of thickness between the MIPs and NIPs.
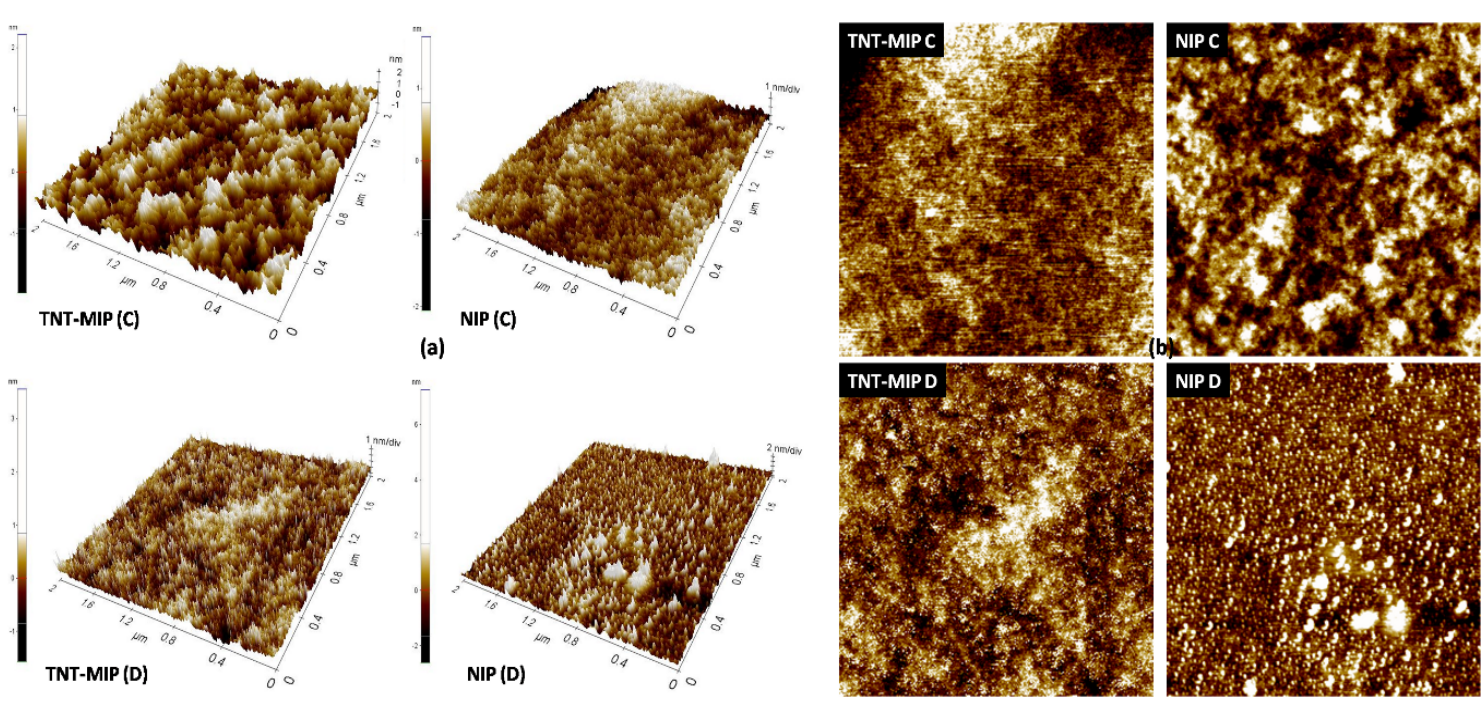

Figure 5. Topography by atomic force microscopy (AFM) of TNT-MIP (C)/ (D) films after TNT extraction, compared to control NIPs $\left(\right.$ scan size $\left.=(2 \times 2) \mu \mathrm{m}^{2}\right)$ : $(\mathbf{a}) 3 \mathrm{D}$ and $(\mathbf{b}) 2 \mathrm{D}$ scans.

In agreement with the topographic measurements, the scanning electron microscopy (Figure 6) highlighted more discrete and homogenous morphology for TNT-MIP (D) films, compared to that of 
(C) films. The surface of both NIPs, (C) and (D) is crossed by a multitude of crevices, which, in terms of sensors applications, means discontinuities in the signal transformation and transfer. The probable cause for their appearance was due to shrinkage during polycondensation/cross-linking and maturation. This shrinkage effect is frequently met during polymerization, as the distance between monomer molecules is gradually shortening due to their addition to the main polymer backbone. In this context, the effect was noticeable for the thick films (C) because the shrinkage occurred in bulk. Nevertheless, the thinner films (D) presented only discrete cracks (NIP (D)) or no cracks at all (TNT-MIP (D) films), as the shrinkage occurred rather lengthwise in this case (Figure 6).
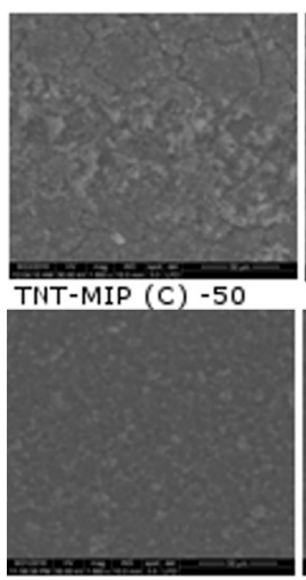

TNT-MIP (D) -50
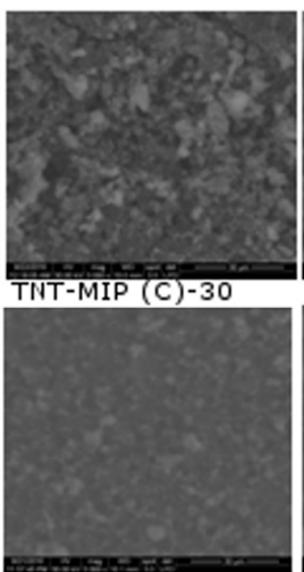

TNT-MIP (D) -30
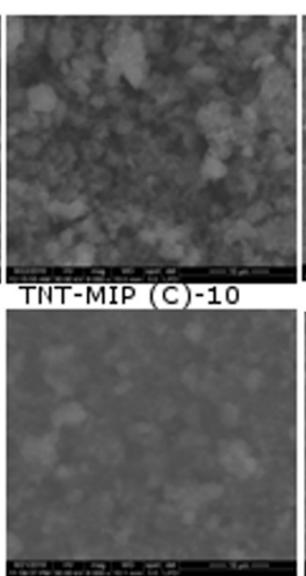

TNT-MIP (D) - 10

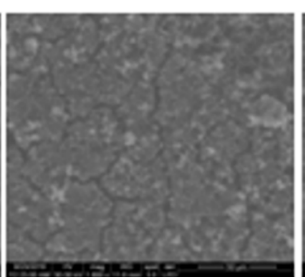

NIP (C) -50

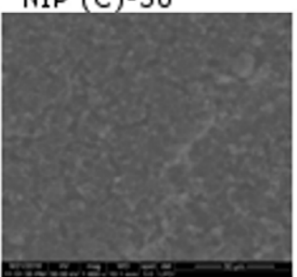

NIP (D) -50

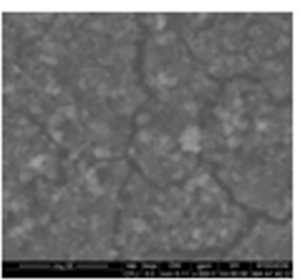

NIP (C) -30

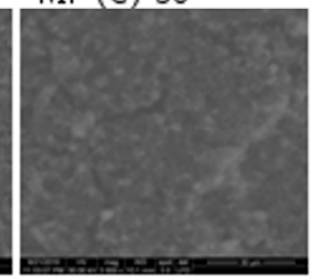

NIP (D) -30

Figure 6. Morphology by scanning electron microscopy (SEM) of TNT-MIP (C)/ (D) films after TNT extraction, compared to control NIPs, at three different magnitude levels (i.e., 50, 30 and $10 \mu \mathrm{m}$ scale).

\subsection{Characterization of Quartz-Cr-Au-TiO ${ }_{2}-\mathrm{MIP}$ Sensors}

The quartz-Cr-Au- $\mathrm{TiO}_{2}-\mathrm{MIP}$ assemblies were prepared in the sequence described in Section 2.3 and characterized using X-ray diffraction and scanning electron microscopy. SEM images of the $\mathrm{Au}$ layer and of $\mathrm{TiO}_{2}$ layers deposited at different temperatures on the quartz-Cr-Au support are shown in Figure $7 \mathrm{a}-\mathrm{c}$. The both types of fabricated films were found to have a grain-like structure. Compared to the surface of $\mathrm{Au}$ (Figure 7a), it was obvious that the layer of $\mathrm{TiO}_{2}$ prepared at $200{ }^{\circ} \mathrm{C}$ covered completely the quartz-Cr-Au support. EDX spectra (Figure 7d-f) indicated the purity degree of the prepared film stack, where only the specific elements used for the preparation of the multilayered support were present, as follows: $\mathrm{Si}, \mathrm{Au}$ and $\mathrm{O}$ for quartz-Cr-Au assembly and $\mathrm{Si}, \mathrm{Au}, \mathrm{O}$, Ti and $\mathrm{O}$ for the quartz-Cr-Au- $\mathrm{TiO}_{2}$ assembly. Notably, the fact that the films deposited at $150{ }^{\circ} \mathrm{C}$ presented lower amounts of Ti and $\mathrm{O}$ (Figure 7e), which may suggest thinner layers or, as confirmed by SEM, discrete areas where the deposition was incomplete [53]. 

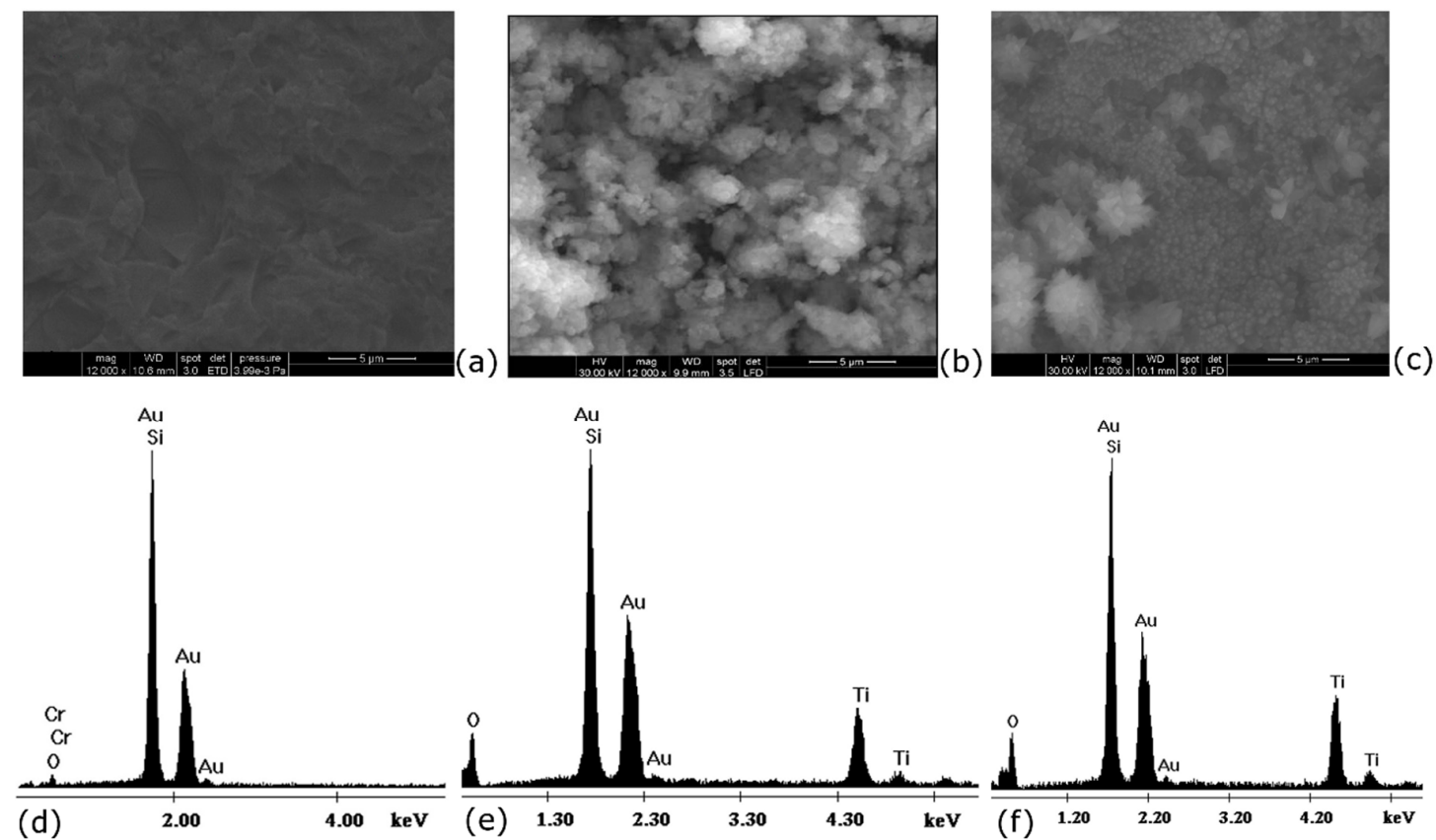

Figure 7. SEM morphologies at $5 \mu \mathrm{m}$ scale together with the corresponding energy dispersive $\mathrm{X}$-ray (EDX) spectra for: (a,d) quartz-Cr-Au support, (b,e) quartz-Cr-Au- $\mathrm{TiO}_{2}$ assembly at $150{ }^{\circ} \mathrm{C}$ and $(\mathbf{c}, \mathbf{f})$ quartz-Cr-Au- $\mathrm{TiO}_{2}$ assembly at $200{ }^{\circ} \mathrm{C}$.

Further on, the diffraction spectra of the two quartz-Cr-Au-TiO $\mathrm{O}_{2}$ assemblies indicated that the hydrothermal treatment performed for the $\mathrm{TiO}_{2}$ preparation did not affect the integrity of the quartz-Cr-Au support (Figure 8a). This was concluded from the presence of Au peaks observed in the XRD patterns of both types of assemblies. The spectrum of quartz-Cr-Au support (Figure 8, inset) revealed the presence of $\mathrm{Au}$ according to the diffraction peaks located at $2 \theta=38.18^{\circ}, 44.62^{\circ}, 64.73^{\circ}$ and $77.93^{\circ}$, which correspond to the crystal plane (111) (200), (220) and (311), respectively [54,55]. The crystalline film sintered at $150^{\circ} \mathrm{C}$ exhibited a single crystallization structure that corresponded to the anatase phase and was identified by the diffraction peaks located at $2 \theta=25.36^{\circ} ; 48.15^{\circ} ; 54,05^{\circ}$ and $55.20^{\circ}$ (crystal plane (101), (200), (105), (211), respectively). On the other hand, the spectrum of $\mathrm{TiO}_{2}$ film synthesized at higher temperatures $200^{\circ} \mathrm{C}$ revealed the presence of anatase, rutile and brookite phase [56]. Rutile phase was identified by the diffraction peaks located at $2 \theta=27.28^{\circ} ; 36.10^{\circ}$; $41.18^{\circ} ; 54.28^{\circ} ; 62.90^{\circ} ; 68.89^{\circ}$ and $69.91^{\circ}$ (crystal plane (110), (100), (111), (211), (002), (301) and (112), respectively) and the weak peak appearing at $2 \theta=30.82^{\circ}(121)$ corresponded to the brookite phase. Although the anatase crystalline phase has the highest electrical conductivity, as it can promote free electrons in the conduction band in the presence of oxygen vacancies [57], a compromise has been made in order to have better control of the particles growth direction and homogenous deposition of the $\mathrm{TiO}_{2}$ film (observed at higher temperatures). Thereby, the $\mathrm{TiO}_{2}$ structure obtained at $200{ }^{\circ} \mathrm{C}$ with an interchange of anatase, rutile and brookite crystalline phases was preferred to prepare the final sensor assemblies. 

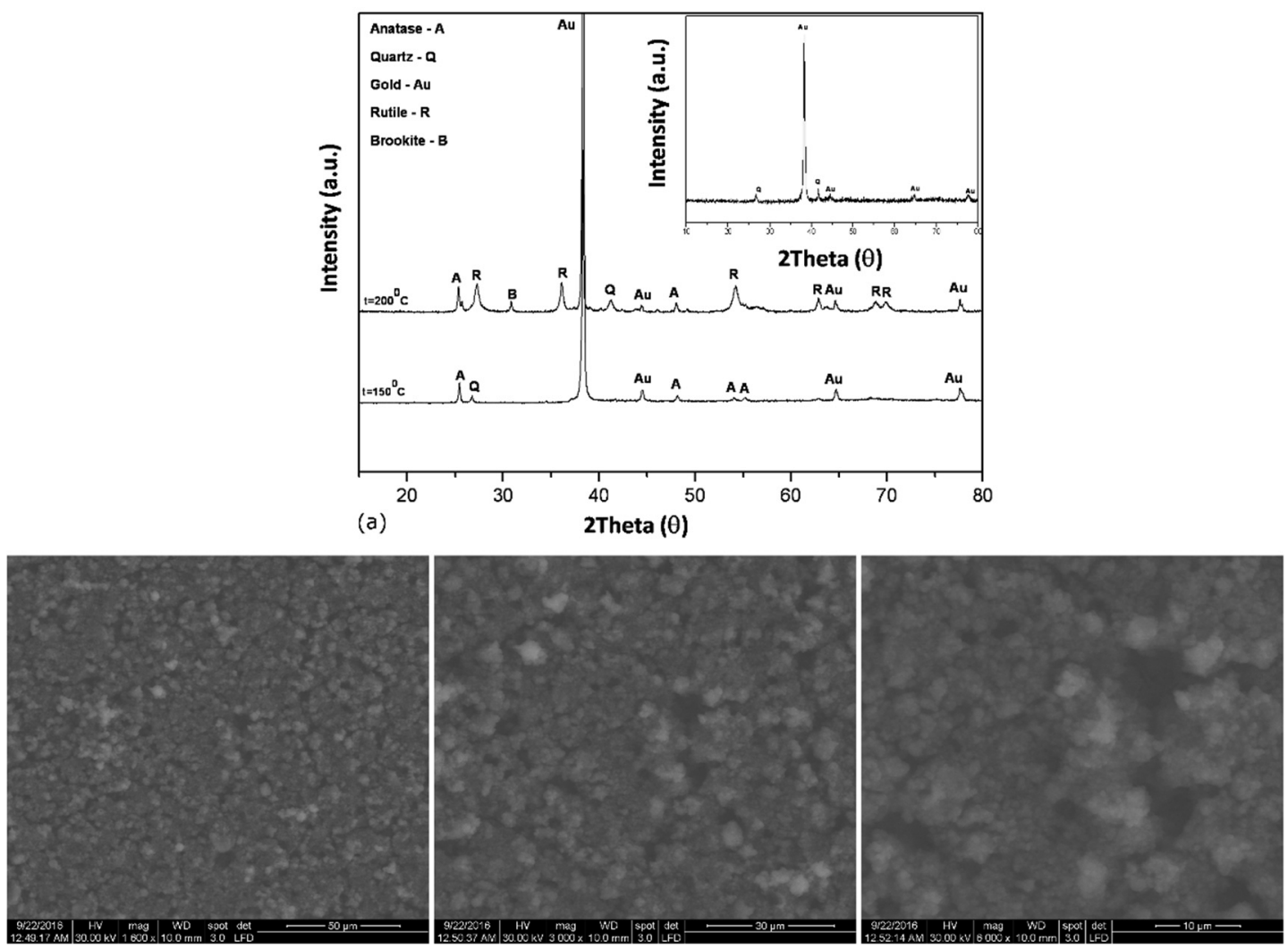

(b) TNT-MIP on quartz-Cr-Au-TiO2

Figure 8. Characteristics of the quartz-Cr-Au- $-\mathrm{TiO}_{2}-\mathrm{MIP}$ assemblies: (a) XRD patterns of quartz-Cr-Au-TiO ${ }_{2}$ support, synthesized at 150 and $200{ }^{\circ} \mathrm{C}$, compared to the patterns of quartz-Cr-Au support alone (inset); (b) Morphology of MIP film deposited on the quartz-Cr-Au-TiO ${ }_{2}$, after TNT extraction, by scanning electron microscopy (SEM), at 50, 30 and $10 \mu \mathrm{m}$ scale, respectively.

Giving the results obtained in batch TNT rebinding experiments, only the TNT-MIP (D) films were used for developing the capacitive sensors, noted quartz-Cr-Au- $\mathrm{TiO}_{2}-\mathrm{MIP}$, and dedicated to the specific measurement of TNT in the vapor state. The micrographs of the MIP film deposited on the quartz-Cr-Au- $\mathrm{TiO}_{2}$ (Figure 8b) showed clear changes of morphology compared to the $\mathrm{TiO}_{2}$ layer in Figure 7c. Plus, the overall morphology of the MIP film deposited on the quartz-Cr-Au-TiO $\mathrm{T}_{2}$ support is more or less consistent with that observed on the glass slide (TNT-MIP (D) film at $50 \mu \mathrm{m}$ scale, Figure 6), considering that deposition was performed on different substrates.

\subsection{TNT Detection in Vapour State Using EM-Quartz-Cr-Au-TiO ${ }_{2}-M I P$ Sensors}

The designed capacitive chemical sensors detect conductivity changes of the MIP sensitive film resulted from the interaction with TNT vapors. Ideal capacitors have no characteristics other than capacitance. However, real capacitors present resistance because of small defects. Hence, using the testing platform described in Section 2.6., identical capacitive sensors, noted EM-quartz-Cr-Au- $\mathrm{TiO}_{2}-\mathrm{MIP}$, were evaluated for resistance $(R)$, capacitance $(C)$, phase angle $(P A$, angle between the voltage and current), impedance $(I)$ and, of course, for the reproducibility at different humidity contents of the gas flow and in the presence of either TNT alone (concentration of $\left.0.2 \mathrm{mg} \cdot \mathrm{L}^{-1}\right)$ or a mixture of TNT and DNB $\left(0.2 / 0.2\left(\mathrm{mg} \cdot \mathrm{L}^{-1} / \mathrm{mg} \cdot \mathrm{L}^{-1}\right)\right)$. The results of the measurements are synthesized in Table 3. The response time of all sensors was less than or equal to $25 \mathrm{~s}$, which states a recommendation for the use of EM-quartz-Cr-Au-TiO2-MIP sensors in threatening situations when fast detection of TNT is required. Furthermore, the variance of capacitance from $5 \%$ to $31 \%$ humidity was small (around $5.6 \mathrm{pF}$ ), and, hence, the sensors may be used beyond isolated environments, with high humidity. 
Table 3. Electrical characteristics $(R(\Omega), C(\mathrm{pF}), P A($ deg. $), I(\Omega)$, and $R t(\mathrm{~s}))$ of EM-quartz-Cr-Au-TiO2-MIP sensors in various conditions (humidity, $H(\%)$, and TNT/DNB ration, $r$ $\left.\left(\mathrm{mg} \cdot \mathrm{L}^{-1} / \mathrm{mg} \cdot \mathrm{L}^{-1}\right)\right)$.

\begin{tabular}{cccccccc}
\hline $\mathbf{N}^{\mathbf{1}}$ & $\boldsymbol{R}$ & $\boldsymbol{C}$ & $\boldsymbol{P A}$ & $\boldsymbol{I}$ & $\boldsymbol{R} \boldsymbol{t}$ & $\boldsymbol{r}$ & $\boldsymbol{H}$ \\
\hline 1 & 192.2 & 163.3 & -78.90 & -974.5 & 21.5 & $0 / 0$ & 5 \\
2 & 198.5 & 166.9 & -78.24 & 953.4 & 24.0 & $0 / 0$ & 31 \\
3 & 234.0 & 329.8 & -64.14 & -482.6 & 23.5 & $2 / 0$ & 5 \\
4 & 234.0 & 329.8 & -64.14 & -482.6 & 25.0 & $2 / 2$ & 5 \\
\hline
\end{tabular}

${ }^{1}$ The raw data for each test set (1 to 4) using identical sensors are given in Figures S5-S8, respectively.

According to Table 3, important variations in the sensors' capacitance (and impedance) were observed in the presence of the TNT contaminant, from $163 \mathrm{pF}$ to $329 \mathrm{pF}$. Considering the fact that all the measurements were performed using concentrated fluxes of TNT vapors, the capacitance variations are appropriate (about $166 \mathrm{pF}$ ). For low concentrations of substance (up to ppm), other capacitance sensors were found to give slight changes of capacitance of around $0.15 \mathrm{pF}$ [58]. Typical capacitance values of capacitors can range from about $1 \mathrm{pF}\left(10^{-12} \mathrm{~F}\right)$ to $1 \mu \mathrm{F}\left(10^{-3} \mathrm{~F}\right)$ [59]. Therefore, the obtained values for capacitance in this study indicated that the combination of the new auto-assembly mechanism with the multi-plate capacitor approach [47] has led to a direct measurement of the out-put signal, without labelling or additional signal amplifiers.

Another important fact referred to the specificity of sensors. The records of TNT retention against DNB showed no change in the sensors' response compared to TNT alone, meaning that the prepared EM-quartz-Cr-Au-TiO2-MIP sensors were specific for TNT. Moreover, during exposure to TNT or DNB vapors, the sensors exhibited stable values for all the measured electrical parameters for over $10 \mathrm{~min}$, which indicated a very good adhesion of the MIP-film to the support. A detachment of the MIP-film from the support would have led to a sharp decrease of capacitance [58].

\section{Conclusions}

To the best of our knowledge, this is the first report depicting the preparation of double Meisenheimer polymerizable complexes for developing TNT-MIP films, which can serve as biomimetic elements for sensors' development. The study provided important insights towards the new auto-assembly mechanism of TNT and diamino-silanes. In this respect, polymerizable double Meisenheimer complexes in the form of 1.53:0.88 = TNT:1141-D (M/M) were generated and used to obtain two sets of molecularly imprinted films, of nearly $200 \mathrm{~nm}$ and of approximately $2 \mu \mathrm{m}$, specific for TNT retention. Spectroscopy measurements revealed important optical changes for TNT-MIP films compared to their control films, which stood as prove for the Meisenheimer complex formation, regardless of the film thickness. The TNT re-binding experiments in liquid state helped evaluating the specificity of films at different feed concentrations of TNT. The results have shown that thinner films were more likely to retain TNT molecules and the most specific binding of TNT ( $F=1.90)$ was registered in the first five min of contact, with a stock solution of $0.02 \mathrm{~g} \cdot \mathrm{L}^{-1}$. Microscopy was a very helpful technique to elucidate the topography and morphology of films, which explained the preferential retention of TNT molecules on thinner MIP films. For determining the extent to which the prepared MIP films can be used for building actual sensors for TNT detection, the MIP thin films were deposited on a multilayer sensor support composed of quartz-Cr-Au- $-\mathrm{TiO}_{2}$ and integrated into an electronic mask (EM). The multilayer sensor support was prepared according to the know-how of co-authors, using the sputtering technique to attach the chromium and gold thin layers on quartz slides and the in situ hydrothermal method to cast the $\mathrm{TiO}_{2}$ films on the formerly prepared quartz-Cr-Au support. Finally, the performance evaluation of EM-quartz-Cr-Au-TiO2-MIP capacitive sensors indicated that they exhibited short response times (less than $25 \mathrm{~s}$ ), low sensitivity to humidity and high specificity for TNT (versus DNB). 


\section{Patents}

The patents released from this work refer to "Trinitrotoluene molecularly imprinted films by sol-gel method and process for their obtaining" (Patent Application OSIM A00144, 2016) and "Process for obtaining titanium dioxide films deposited on noble metal substrates, using the classical hydrothermal method" Patent RO132256, 2019.

Supplementary Materials: The following are available online at http://www.mdpi.com/2079-6412/10/3/273/s1, Figure S1: Films on glass slides, Figure S2: Schematic illustration of the in-situ hydrothermal method; Figure S3: Description of the sensor assembly; Figure S4: TNT-MIP (D) films and NIP (D) after 120 min of contact with the TNT solution $0.02 \mathrm{~g} \mathrm{~L}^{-1}$; Figure S5: Experimental data (RLC) for sensors tests in vapour state- Test Set $\mathrm{N}^{\mathrm{o}} 1$; Figure S6: Experimental data (RLC) for sensors tests in vapour state- Test Set $N^{\circ} 2$; Figure S7: Experimental data (RLC) for sensors tests in vapour state- Test Set $N^{\circ} 3$; Figure S8: Experimental data (RLC) for sensors tests in vapour stateTest Set $\mathrm{N}^{0} 4$.

Author Contributions: Conceptualization, A.S., C.L., and T.V.I.; methodology, A.M.G., I.C. and T.R.; formal analysis, A.M.G., M.S. and H.S.; investigation, C.O. and C.E.B.; writing-original draft preparation, T.V.I.; writing-review and editing, T.V.I.; visualization, A.S.; supervision, A.S.; project administration, C.L., A.S., T.V.I.; funding acquisition, C.L. and T.V.I. All authors have read and agreed to the published version of the manuscript.

Funding: The study was funded by the Romanian Funding Agency UEFISCDI, through the supporting projects SENZOREX no. 291/2014, BACTERIOSENS no. TE 123/2018, and SECURE-NET, no. 70PCCDI/2018 and the APC was funded by Project no. 70PCCDI/2018.

Conflicts of Interest: The authors declare no conflict of interest. The funders had no role in the design of the study; in the collection, analyses, or interpretation of data; in the writing of the manuscript, or in the decision to publish the results.

\section{References}

1. Lu, L.Q.; Zheng, Y.; Qu, W.G.; Xu, A.W. Convenient and sensitive synchronous fluorescence detection of trace TNT based on FRET using FITC-PAH as a probe. Anal. Methods 2013, 5, 603-607. [CrossRef]

2. Ban, R.; Zheng, F.; Zhang, J. A highly sensitive fluorescence assay for 2,4,6-trinitrotoluene using amine-capped silicon quantum dots as a probe. Anal. Methods 2015, 7, 1732-1737. [CrossRef]

3. Tu, R.Y.; Liu, B.H.; Wang, Z.Y. Amine-capped ZnS-Mn2+nanocrystals for fluorescence detection of trace TNT explosive. Anal. Chem. 2008, 80, 3458-3465. [CrossRef] [PubMed]

4. Li, H.H.; Lü, F.T.; Zhang, S.J. Preparation of monolayer-assembled fluorescent film and its sensing performances to hidden nitroaromatic explosives. Chin. Sci. Bull. 2008, 53, 1644-1650.

5. Sohn, H.; Sailor, M.J.; Magde, D. Detection of nitroaromatic explosives based on photoluminescent polymers containing metalloles. J. Am. Chem. Soc. 2003, 125, 3821-3830. [CrossRef] [PubMed]

6. Dasary, S.S.R.; Singh, A.K.; Senapati, D.; Yu, H.T.; Ray, P.C. Gold nanoparticle based label-free SERS probe for ultrasensitive and selective detection of trinitrotoluene. J. Am. Chem. Soc. 2009, 131, 13806-13812. [CrossRef] [PubMed]

7. Hughes, S.; Dasary, S.S.; Begum, S.; Williams, N.; Yu, H. Meisenheimer complex between 2,4,6-trinitrotoluene and 3-aminopropyltriethoxysilane and its use for a paper-based sensor. Sens. Biosensing Res. 2015, 5, 37-41. [CrossRef]

8. Altstein, M.; Bronshtein, A.; Glattstein, B.; Zeichner, A.; Tamiri, T.; Almog, J. Immunochemical approaches for purification and detection of TNT traces by antibodies entrapped in a sol-gel matrix. Anal. Chem. 2001, 73, 2461-2467. [CrossRef]

9. Ewing, R.G.; Atkinson, D.A.; Eiceman, G.A.; Ewing, G.J. A critical review of ion mobility spectrometry for the detection of explosives and explosive related compounds. Talanta 2001, 54, 515-529. [CrossRef]

10. Asbury, G.R.J.; Klasmeier, H.H.; Hill, J. Analysis of explosives using electrospray ionization/ ion mobility spectrometry (ESI/IMS). Talanta 2000, 50, 1291-1298. [CrossRef]

11. Zhou, H.B.; Zhang, Z.P.; Jiang, C.L.; Guan, G.J.; Zhang, K.; Mei, Q.S.; Liu, R.Y.; Wang, S.H. Trinitrotoluene explosive lights up ultrahigh Raman scattering of nonresonant molecule on a top-closed silver nanotube array. Anal. Chem. 2011, 6913-6917. [CrossRef] [PubMed]

12. Ali, E.M.A.; Edwards, H.G.M.; Scowen, I.J. Raman spectroscopy and security applications: The detection of explosives and precursors on clothing. J. Raman Spectrosc. 2009, 40, 2009-2014. [CrossRef] 
13. He, X.; Wang, H.; Li, Z.; Chen, D.; Zhang, Q. ZnO-Ag hybrids for ultrasensitive detection of trinitrotoluene by surface-enhanced Raman spectroscopy. Phys. Chem. Chem. Phys. 2014, 16, 14706-14712. [CrossRef] [PubMed]

14. Qu, W.G.; Deng, B.; Zhong, S.L.; Shi, H.Y.; Wang, S.S.; Xu, A.W. Plasmonic resonance energy transfer-based nanospectroscopy for sensitive and selective detection of 2,4,6-trinitrotoluene (TNT). Chem. Commun. 2011, 47, 1237-1239. [CrossRef] [PubMed]

15. Riskin, M.; Tel-Vered, R.; Lioubashevski, O.; Willner, I. Ultrasensitive surface plasmon resonance detection of trinitrotoluene by a bis-aniline-cross-linked Au nanoparticles composite. J. Am. Chem. Soc. 2009, 131, 7368-7378. [CrossRef] [PubMed]

16. Giustina, G.D.; Sonato, A.; Gazzola, E.; Ruffato, G.; Brusa, S.; Romanato, F. SPR Enhanced molecular imprinted sol-gel film: A promising tool for gas-phase TNT detection. Mat. Let. 2016, 162, 44-47. [CrossRef]

17. Ekberg, B.; Mosbach, K. Molecular imprinting: A technique for producing specific separation materials. Trends Biotech. 1989, 7, 92-96. [CrossRef]

18. Whitcombe, M.J.; Kirsch, N.; Nicholls, I.A. Molecular imprinting science and technology: A survey of the literature for the years 2004-2011. J. Mol. Recognit. 2014, 27, 297-401.

19. Bird, L.; Herdes, C. The porogen effect on the complexation step of trinitrotoluene-methacrylic acid: Towards efficient imprinted polymer sensors. Mol. Syst. Des. Eng. 2018, 3, 73-88. [CrossRef]

20. Herdes, C.; Sarkisov, L. Computer simulation of volatile organic compound adsorption in atomistic models of molecularly imprinted polymers. Langmuir 2009, 25, 5352-5359. [CrossRef]

21. Ertürk, G.; Mattiasson, B. Molecular imprinting techniques used for the preparation of biosensors. Sensors (Basel) 2017, 17, pii: E288.

22. Chen, L.; Xua, S.; Li, J. Recent advances in molecular imprinting technology: Current status, challenges and highlighted applications. Chem. Soc. Rev. 2011, 40, 2922-2942. [CrossRef] [PubMed]

23. Kupai, J.; Razali, M.; Buyuktiryaki, S.; Kecili, R.; Szekely, G. Long-term stability and reusability of molecularly imprinted polymers. Polymer Chem. 2017, 8, 666-673. [CrossRef] [PubMed]

24. Sarbu, A.; Iordache, T.V.; Florea, A.M.; Apostol, S.; Sandu, T.; Lazau, C.; Radu, A.L.; Nita, G. Trinitrotoluene Molecularly Imprinted Polymer films deposited onto TiO2 support and obtaining process. Patent RO 131692 B1 2018.

25. Kalivretenos, A.G.; Van Houten, K.A.; Gluckman, J.P.; Hardy, F.M.; Dorovskoy, I.P.; Trower, R. Molecularly-imprinted polymeric materials for visual detection of explosives. Patent WO2010078426A9 18 November 2010.

26. Sarbu, A.; Iordache, T.V.; Florea, A.M.; Apostol, S.; Sandu, T.; Lazau, C.; Bandas, C.E.; Orha, C.I.; Rotariu, T.; Voicu, E.A.; et al. Trinitrotoluene molecularly imprinted films by sol-gel method and process for their obtaining. Patent Application OSIM A00144 2016.

27. Lazau, C.; Iordache, T.V.; Florea, A.M.; Orha, C.; Bandas, C.; Radu, A.L.; Sarbu, A.; Rotariu, T. Towards developing an efficient sensitive element for trinitrotoluene detection: $\mathrm{TiO}_{2}$ thin films functionalized with molecularly imprinted copolymer films. Appl. Surf. Sci. 2016, 384, 449-458. [CrossRef]

28. Lazau, C.; Bandas, C.; Orha, C. Process for obtaining titanium dioxide films deposited on noble metal substrates, using the classical hydrothermal method. Patent RO132256 2019.

29. Florea, A.M.; Iordache, T.V.; Branger, C.; Ghiurea, M.; Avramescu, S.; Hubca, G.; Sarbu, A. An innovative approach to prepare hypericin molecularly imprinted pearls using a phyto-template. Talanta 2016, 148, 37-45. [CrossRef] [PubMed]

30. Udomsap, D.; Branger, C.; Culiol, G.; Dollet, P.; Brisset, H. A versatile electrochemical sensing receptor based on a molecularly imprinted polymer. Chem. Commun. 2014, 50, 7488-7491. [CrossRef]

31. Li, D.Y.; He, X.W.; Chen, Y.; Li, W.Y.; Zhang, Y.K. Novel hybrid structure silica/CdTe/molecularly imprinted polymer: Synthesis, specific recognition, and quantitative fluorescence detection of bovine hemoglobin. ACS Appl. Mater. Interfaces 2013, 23, 12609-12616. [CrossRef]

32. Takeuchi, T.; Kitayama, Y.; Sasao, R.; Yamada, T.; Toh, K.; Matsumoto, Y.; Kataoka, K. Molecularly imprinted nanogels acquire stealth in situ by cloaking themselves with native dysopsonic proteins. Angew. Chem. Int. Ed. 2017, 56, 7088-7092. [CrossRef]

33. Bertolla, M.; Cenci, L.; Anesi, A.; Ambrosi, E.; Tagliaro, F.; Vanzetti, L.; Guella, G.; Bossi, A.M. Solvent-responsive molecularly imprinted nanogels for targeted protein analysis in MALDI-TOF Mass Spectrometry. ACS Appl. Mater. Interfaces 2017, 9, 6908-6915. [CrossRef] 
34. Boysen, R.I.; Schwarz, L.J.; Nicolau, D.V.; Hearn, M.T. Molecularly imprinted polymer membranes and thin films for the separation and sensing of biomacromolecules. J. Sep. Sci. 2017, 40, 314-335. [CrossRef] [PubMed]

35. Mujahid, A.; Lieberzeit, P.A.; Dickert, F.L. Chemical sensors based on molecularly imprinted sol-gel materials. Materials 2010, 3, 2196-2217. [CrossRef]

36. Florea, A.M.; Iordache, T.V.; Branger, C.; Brisset, H.; Zaharia, A.; Radu, A.L.; Hubca, G.; Sarbu, A. One-step preparation of molecularly imprinted hollow beads for pseudohypericin separation from Hypericum perforatum L. Extracts. Eur. Polym. J. 2018, 100, 48-56. [CrossRef]

37. Nakai, S.; Sunayama, H.; Kitayama, Y.; Nishijima, M.; Wada, T.; Inoue, Y.; Takeuchi, T. Regioselective molecularly imprinted reaction field for $[4+4]$ photocyclodimerization of 2-anthracenecarboxylic acid. Langmuir 2017, 33, 2103-2108. [CrossRef] [PubMed]

38. Piletsky, S.A.; Whitcombe, M.J. Designing Receptors for the Next Generation of Biosensors, 1st ed.; Springer Series on Chemical Sensors and Biosensors: Berlin/Heidelberg, Germany, 2013; pp. 1-256.

39. Di Bello, M.P.; Lazzoi, M.R.; Mele, G.; Scorrano, S.; Mergola, L.; Del Sole, R. A New Ion-Imprinted Chitosan-Based Membrane with an Azo-Derivative Ligand for the Efficient Removal of Pd(II). Materials 2017, 10, 1133. [CrossRef]

40. Du, X.; Guan, G.; Li, X.; Jagadale, A.D.; Ma, X.; Wang, Z.; Hao, X.; Abudul, A. A novel electroactive $\lambda$-MnO2/PPy/PSS core-shell nanorod coated electrode for selective recovery of lithium ions at low concentration. J. Mater. Chem. A 2016, 4, 13989-13996. [CrossRef]

41. Öncel, P.; Çetin, K.; Topçu, A.A.; Yavuz, H.; Denizli, A. Molecularly imprinted cryogel membranes for mitomycin C delivery. J. Biomater. Sci. Polym. Ed. 2017, 28, 519-531. [CrossRef]

42. Székely, G.; Valtcheva, I.B.; Kim, J.F.; Livingston, A.G. Molecularly imprinted organic solvent nanofiltration membranes-Revealing molecular recognition and solute rejection behavior. React. Funct. Polym. 2015, 86, 215-224. [CrossRef]

43. Gao, D.; Zhang, Z.; Wu, M.; Xie, C.; Guan, G.; Wang, D. A surface functional monomer-directing strategy for highly dense imprinting of TNT at surface of silica nanoparticles. J. Am. Chem. Soc. 2007, 129, 7859-7866. [CrossRef]

44. Xie, C.; Zhang, Z.; Wang, D.; Guan, G.; Gao, D.; Liu, J. Surface molecular self-assembly strategy for TNT imprinting of polymer nanowire/nanotube arrays. Anal. Chem. 2006, 78, 8339-8346. [CrossRef]

45. Janata, J. Principles of Chemical Sensors, 2nd ed.; Springer: Berlin/Heidelberg, Germany, 2009; pp. 99-266.

46. Kreno, L.E.; Leong, K.; Farha, O.K.; Allendorf, M.; Van Duyne, R.P.; Hupp, J.T. Metal-Organic Framework Materials as Chemical Sensors. Chem. Rev. 2012, 112, 1105-1125. [CrossRef] [PubMed]

47. Terzic, E.; Terzic, J.; Nagarajah, R.; Alamgir, M. (Eds.) Capacitive Sensing Technology. In A Neural Network Approach to Fluid Quantity Measurement in Dynamic Environments; Springer: Berlin/Heidelberg, Germany, 2012; pp. 11-37.

48. Xu, B.; Wu, X.; Li, H.; Tong, H.; Wang, L. Selective Detection of TNT and Picric Acid by Conjugated Polymer Film Sensors with Donor-Acceptor Architecture. Macromolecules 2011, 44, 5089-5092. [CrossRef]

49. Stoica, E.B.; Gavrila, A.M.; Branger, C.; Brisset, H.; Dyshlyuk, A.V.; Vitrik, O.B.; Iovu, H.; Sarbu, A.; Iordache, T.V. Evaluation of Molecularly Imprinted Thin Films for Ephedrine recognition. Mater. Plast. 2019, 4, 865-874. [CrossRef]

50. Martelo, L.M.; Marques, L.F.; Burrows, H.D.; Berberan-Santos, M.N. Fluorescence in Industry. In Explosives Detection: From Sensing to Response; Bruno, P., Ed.; Springer: Cham, Switzerland, 2019; Volume 18, pp. $293-320$.

51. Fang, Y.; Furniss, D.; Jayasuriya, D.; Parnell, H.; Tang, Z.Q.; Gibson, D.; Bayya, S.; Sanghera, J.; Seddon, A.B.; Benson, T.M. Methods for determining the refractive indices and thermo-optic coefficients of chalcogenide glasses at MIR wavelengths. Opt. Mater. X 2019, 2, 100030. [CrossRef]

52. El Kirat, K.; Bartkowski, M.; Haupt, K. Probing the recognition specificity of a protein molecularly imprinted polymer using force spectroscopy. Biosens. Bioelectron. 2009, 24, 2618-2624. [CrossRef] [PubMed]

53. Iatsunskyi, I.; Jancelewicz, M.; Nowaczyk, G.; Kempiński, M.; Peplińska, B.; Jarek, M.; Załęski, K.; Jurga, S.; Smyntyna, V. Atomic layer deposition $\mathrm{TiO} 2$ coated porous silicon surface: Structural characterization and morphological features. Thin Solid Films 2015, 589, 303-308. [CrossRef]

54. Ragazzon, D.; Farstad, M.H.; Schaefer, A.; Walle, L.E.; Uvdal, P.; Borg, A.; Sandell, A. Growth of TiO $2(B)(001)$ on $\mathrm{Au}(111)$ by chemical vapor deposition. Surf. Sci. 2015, 633, 102-108. [CrossRef] 
55. Grunwaldt, J.D.; Göbel, U.; Baiker, A. Preparation and characterization of thin TiO2-films on gold/mica. Fresenius J. Anal. Chem. 1997, 358, 96-100. [CrossRef]

56. Allen, N.S.; Mahdjoub, N.; Vishnyakov, V.; Kelly, P.J.; Kriek, R.J. The effect of crystalline phase (anatase, brookite and rutile) and size on the photocatalytic activity of calcined polymorphic titanium dioxide $\left(\mathrm{TiO}_{2}\right)$. Polym. Degrad. Stab. 2018, 150, 31-36. [CrossRef]

57. Folger, A.; Kalb, J.; Schmidt-Mende, L.; Scheu, C. Tuning the Electronic Conductivity in Hydrothermally Grown Rutile TiO2 Nanowires: Effect of Heat Treatment in Different Environments. Nanomaterials (Basel) 2017, 7, 289. [CrossRef]

58. Kavalenka, M.N.; Striemera, C.C.; DesOrmeaux, J.P.S.; McGrath, J.L.; Fauchet, P.M. Chemical capacitive sensing using ultrathin flexible nanoporous electrodes. Sens. Actuators B Chem. 2012, 162, 22-26. [CrossRef]

59. Scherz, P. Practical Electronics for Inventors, 4th ed.; McGraw-Hill Professional Publishing: New York, NY, USA, 2000; Chapter 2.

(C) 2020 by the authors. Licensee MDPI, Basel, Switzerland. This article is an open access article distributed under the terms and conditions of the Creative Commons Attribution (CC BY) license (http://creativecommons.org/licenses/by/4.0/). 